\title{
MAXIMUM POWER TRACKING OF A GRID-CONNECTED WIND-DRIVEN BRUSHLESS DOUBLY-FED RELUCTANCE GENERATOR USING SCALAR CONTROL
}

\author{
Mohamed G. Mousa, S. M. Allam, ,Essam M. Rashad \\ Department of Electrical Power and Machines Engineering, Faculty of Engineering, Tanta \\ University, Egypt
}

\begin{abstract}
:
This paper presents a scalar volt per hertz (v/f) control technique for maximum power tracking of a grid-connected wind-driven Brushless Doubly-Fed Reluctance Generator (BDFRG). The proposed generator has two stator windings namely; power winding, directly connected to the grid, and control winding, connected to the grid through a bi-directional converter. The presented control technique is based on the abc-axis and dq-axis dynamic model of BDFRG. A detailed abc-axis and dq-axis dynamic model, by which the dynamic behaviour of the BDFRG can be successfully predicted under different operating conditions, is presented. In addition, a soft starting method is suggested to avoid the over-current of the bi-directional converter. The presented simulation results ensure the effectiveness of the proposed control strategy for maximum wind-power extraction under wind-speed variations.
\end{abstract}

Keywords: Brushless doubly-fed reluctance generator; wind-power generation systems; soft starting; scalar V/f control; maximum wind-power extraction

$\begin{array}{ll}\begin{array}{c}\text { Nomenclature } \\ \mathrm{L}_{\mathrm{pc}_{\max }}\end{array} & \text { peak mutual inductance between power and control windi } \\ B_{r}, B_{g} & \text { wind turbine and BDFRG friction coefficient } \\ I_{r}, J_{g} & \text { wind turbine and BDFRG moment of inertia } \\ L_{l_{c}} & \text { leakage inductance of control winding } \\ L_{l_{p}} & \text { leakage inductance of power winding } \\ L_{m_{e}} & \text { magnetizing inductance of control winding } \\ L_{m_{p}} & \text { magnetizing inductance of power winding } \\ V_{a b b_{c}} & \text { three-phase voltages of control winding } \\ V_{a b c_{p}} & \text { three-phase voltages of power winding } \\ V_{d_{c}}, V_{q_{c}} & \text { control winding dq-axis voltage components } \\ V_{d_{p}}, V_{q_{p}} & \text { power winding dq-axis voltage components } \\ V_{w} & \text { wind speed (m/s) }\end{array}$




$\begin{array}{ll}f_{p}, f_{c} & \text { power and control winding frequencies } \\ i_{a b c_{c}} & \text { three-phase currents of control winding } \\ i_{a b c_{p}} & \text { three-phase currents of power winding } \\ i_{d_{c},}, i_{q_{c}} & \text { control winding dq-axis current components } \\ i_{d_{p},}, i_{q_{p}} & \text { power winding dq-axis current components } \\ n_{g} & \text { gearbox ratio } \\ r_{p}, r_{c} & \text { power and control winding resistances } \\ \theta_{f} & \text { mechanical position of reference frame } \\ \theta_{r m} & \text { BDFRG mechanical rotor position } \\ \lambda_{a b c_{c}} & \text { three-phase flux linkages of control winding } \\ \lambda_{a b c_{p}} & \text { three-phase flux linkages of power winding } \\ \lambda_{d_{c},}, \lambda_{q_{c}} & \text { control winding dq-axis flux components } \\ \lambda_{d_{p},}, \lambda_{q_{p}} & \text { power winding dq-axis flux components } \\ \omega_{f} & \text { mechanical angular speed of reference frame } \\ \omega_{r m} & \text { BDFRG mechanical rotor angular speed } \\ \beta, \rho & \text { blade pitch-angle and air density } \\ R & \text { wind turbine blade radius }\end{array}$

\section{Introduction}

In recent years, wind power has been gaining renewed interest due to an increased emphasis on environmentally sustainable resources as well as progress in wind related technologies [1]. Over the past two decades, a variety of wind power technologies have been developed, which have improved the wind-power conversion efficiency [2]. One of these technologies has been the introduction of new types of generators to be used in wind-generating systems. The wind-turbine generators convert the wind kinetic-energy into electric power and injecting this electric power into the utility grid. Different generator types have been used in wind-generating systems over the years. These include the squirrel- cage induction generator, doubly-fed induction generator and synchronous generator (wound rotor and permanent magnet) with power ratings from a few kilowatts to several megawatts [2].

Wind turbines can be classified into fixed-speed and variable-speed turbines [2]. The main drawback of fixed-speed turbines is that the maximum power-conversion efficiency can be achieved only at a certain wind speed. However, variable-speed wind turbines can achieve maximum power-conversion efficiency over a wide range of wind speeds, since the turbine can continuously adjust its rotational speed according to the wind speed. In order to make the turbine speed adjustable, the wind-turbine generator is normally connected to the utility grid through a power electronic converter. The converter enables the control of the generator speed that is mechanically coupled to the rotor (blades) of the wind turbine. The power rating of the converter is normally the same as that of the generator [2]. This results in increasing the overall system cost. 
Brushless Doubly-Fed Machine (BDFM) is a special form of slip recovery machines that reduce the capacity of the required converter to be used if the required speed-control range is limited. This will lead to a significant reduction in the drive-system cost [3]. Therefore, the use of this type of machines would be a cost-effective one that should be used in variable-speed windgenerating systems.

The BDFM represents a development of self-cascaded machines with two three-phase stator windings having different number of poles accommodated in a single machine frame [3]. Recent developments in the area of doubly-fed machines have revitalised research activities into this type of electric machine [4]. The Brushless Doubly-Fed Induction Machine (BDFIM) and the Brushless Doubly-Fed Reluctance Machine (BDFRM) are the two main competitors attracting most of the attention from researchers [4]. The rotor design of both BDFIM and BDFRM ensures robustness, reliability, and maintenance-free operation. However, the efficiency of the BDFRM is expected to be superior to the BDFIM due to the lack of rotor copper losses [4]. Therefore, the Brushless Doubly-Fed Reluctance Generator (BDFRG) is found to be the most attractive one for wind-power generation systems. The background and fundamental structure of the BDFRM was described in [5]-[6]. In addition, the machine dynamic model has already been established in [6] based on the space-vector theory.

Very little work has been presented on the development of BDFRG in wind-power generation systems [7]-[8]. Moreover, in order to extract the maximum power from the wind turbine, different control techniques are proposed [7]-[8]. However, the use of scalar V/f control technique to achieve the maximum wind-power extraction for a wind-driven BDFRG system has not recorded any attention from researchers until to date.

In this paper, a scalar $\mathrm{V} / \mathrm{f}$ control method is proposed for maximum wind-power extraction under wind-speed variations of a grid-connected wind-driven BDFRG system. A detailed abc-axis and dq-axis dynamic model of the BDFRG is presented. In addition, a soft starting method is suggested to avoid the converter over-current.

\section{Main Construction of BDFRM}

The BDFRM has two stator windings with different number of poles in order to avoid direct transformer coupling between the two windings. In addition, the stator windings must differ by more than one to avoid unbalanced magnetic pull on the rotor [4]. The primary winding (called the power winding with $P_{p}$ pole-pairs) is directly connected to the grid and the secondary winding (called the control winding with $P_{c}$ pole-pairs) is connected to the grid through a bi-directional acdc-ac converter. The conceptual diagram of the BDFRG is shown in Fig. 1.

The number of poles of the reluctance rotor is governed by the summation of the pole-pairs of the two stator windings in order to get a rotor position dependent mutual coupling between the two stator windings. The resultant mutual inductance variation with rotor position causes a change of co-energy as well as torque production [4]. The electro-mechanical energy conversion can occur only at a particular speed [5]. This speed is given by:

$$
\omega_{r m}=\frac{2 \pi\left(f_{p} \pm f_{c}\right)}{P_{p}+P_{c}}
$$

The ' \pm ' signs denote the same (+ve. sign) and opposite (-ve. sign) sequence of the control winding with respect to that of the power winding respectively. 


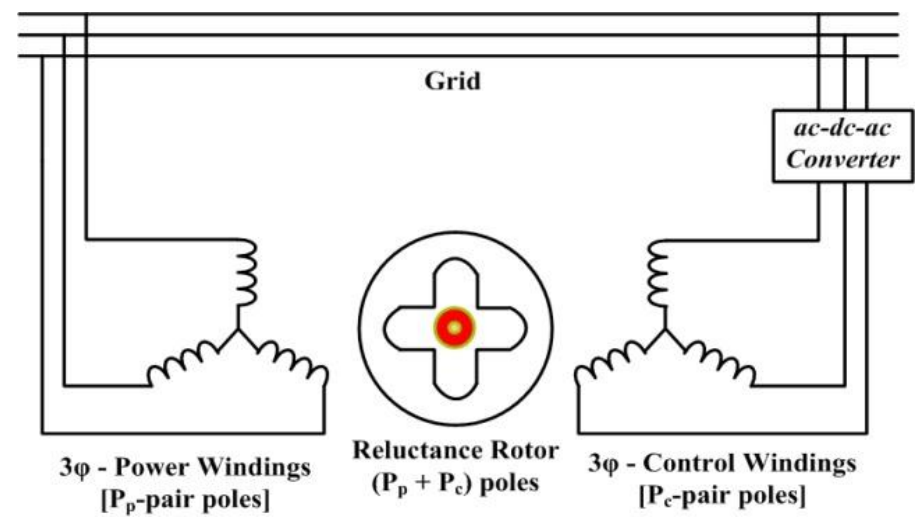

Fig. 1. Conceptual diagram of the BDFRM

\section{Grid-Connected Wind-Driven BDFRG System}

Fig. 2 illustrates a simple configuration of the proposed grid-connected wind-driven BDFRG system. The wind turbine is mechanically coupled to the rotor shaft of the BDFRG through a stepup gearbox. The auxiliary switches $S_{1}$ and $S_{2}$ are used for soft starting purpose in order to protect the bi-directional converter from over current during starting period.

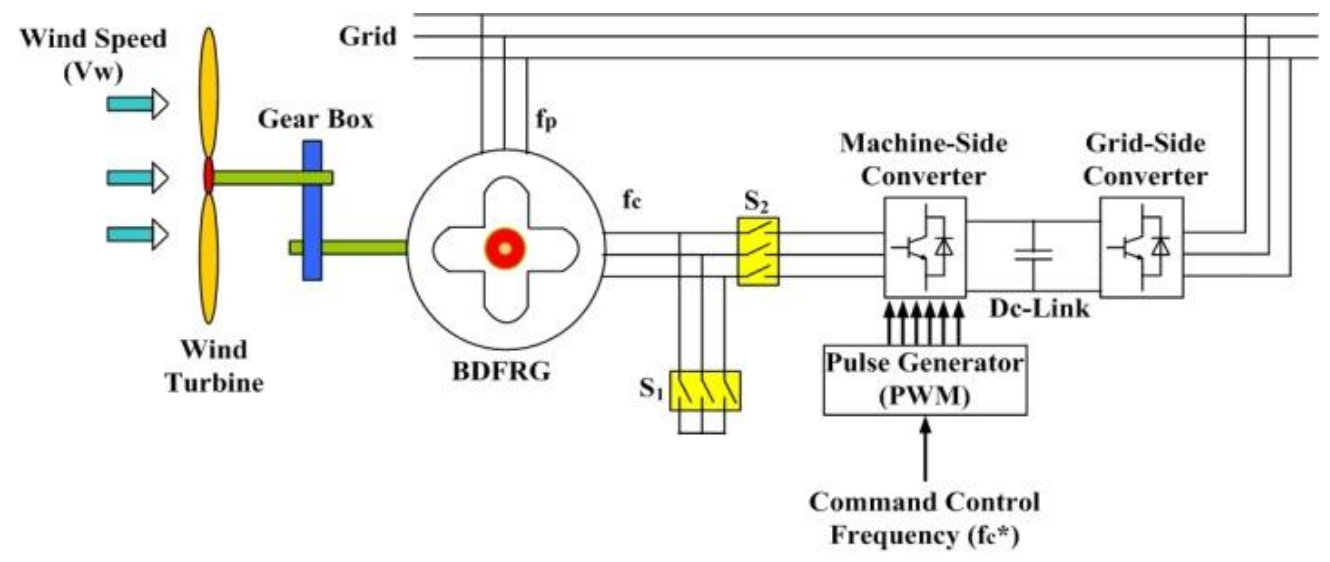

Fig.2.Grid-connected wind-driven BDFRG system

\subsection{Wind Turbine Characteristics}

The wind turbine is used to convert the kinetic energy associated with the wind energy into mechanical energy. The mechanical power captured from the wind energy by the wind turbine can be expressed as [9]:

$$
P_{m}=0.5 * \rho * \pi * R^{2} * C_{p}(\lambda, \beta) * V_{w}^{3}
$$

The turbine tip-speed ratio, $\lambda$ is given by: 


$$
\lambda=\left(\frac{R * \omega_{r m}}{V_{w} * n_{g}}\right)
$$

In addition, the wind-turbine power coefficient, $C_{p}$ can be written, in terms of the turbine tipspeed ratio, $\lambda$ and the blade pitch-angle, $\beta$ as [9]:

$$
C_{p}(\lambda, \beta)=0.5176\left(\frac{116}{\lambda_{x}}-0.4 \beta-5\right) e^{-\frac{21}{\lambda_{x}}}+0.0068 \lambda
$$

$$
\begin{aligned}
& \text { where } \\
& \frac{1}{\lambda_{x}}=\frac{1}{\lambda+0.08 \beta}-\frac{0.035}{\beta^{3}+1}
\end{aligned}
$$

The mechanical output torque of wind turbine is given by:

$$
T_{t}=\frac{P_{m} * n_{g}}{\omega_{r m}}
$$

Fig. 3 shows the characteristics of the wind turbine power coefficient with the tip-speed ratio at different values of the blade pitch-angle.

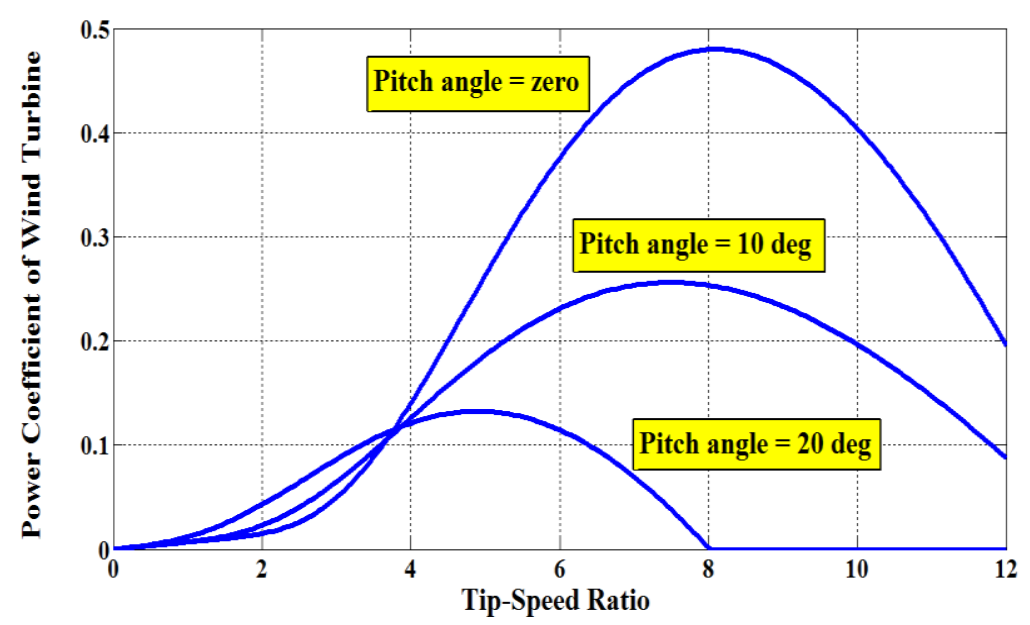

Fig. 3. Characteristics of the wind turbine power coefficient with the tip-speed ratio at different values of the blade pitch-angle

It is clear from the figure that there is a certain value of the tip-speed ratio at which the power coefficient is maximized. This value is known as the optimal value of the tip-speed ratio, $\lambda_{\text {opt }}$. Hence, a maximum mechanical power can be obtained from the wind turbine.

\subsection{System Dynamic Modeling}

The abc-axis dynamic model of the BDFRG can be summarized as follows [5]-[6]:

The three-phase voltage equations of the power and control windings can be written, in a matrix form, as:

$$
V_{a b c_{p}}=R_{p} * i_{a b c_{p}}+\frac{d}{d t} \lambda_{a b c_{p}}
$$


$V_{a b c_{c}}=R_{c} * i_{a b c_{c}}+\frac{d}{d t} \lambda_{a b c_{c}}$

where

$$
\begin{aligned}
& R_{p}=\left(\begin{array}{ccc}
r_{p} & 0 & 0 \\
0 & r_{p} & 0 \\
0 & 0 & r_{p}
\end{array}\right) \\
& R_{c}=\left(\begin{array}{ccc}
r_{c} & 0 & 0 \\
0 & r_{c} & 0 \\
0 & 0 & r_{c}
\end{array}\right)
\end{aligned}
$$

In addition, the flux linkage relations of the two-stator windings are given by:

$$
\begin{aligned}
& \lambda_{a b c_{p}}=L_{a b c_{p}-a b c_{p}} * i_{a b c_{p}}+L_{a b c_{p}-a b c_{c}} * i_{a b c_{c}} \\
& \lambda_{a b c_{c}}=L_{a b c_{c}-a b c_{c}} * i_{a b c_{c}}+L_{a b c_{c}-a b c_{p}} * i_{a b c_{p}}
\end{aligned}
$$

where

$$
\begin{aligned}
& L_{a b c_{p}-a b c_{p}}=\left(\begin{array}{lll}
L_{l p}+L_{m p} & -0.5 L_{m p} & -0.5 L_{m p} \\
-0.5 L_{m p} & L_{l p}+L_{m p} & -0.5 L_{m p} \\
-0.5 L_{m p} & -0.5 L_{m p} & L_{l p}+L_{m p}
\end{array}\right) \\
& L_{a b c_{c}-a b c_{c}}=\left(\begin{array}{lll}
L_{l c}+L_{m c} & -0.5 L_{m c} & -0.5 L_{m c} \\
-0.5 L_{m c} & L_{l c}+L_{m c} & -0.5 L_{m c} \\
-0.5 L_{m c} & -0.5 L_{m c} & L_{l c}+L_{m c}
\end{array}\right) \\
& L_{a b c_{p}-a b c_{c}}=\left(\begin{array}{lll}
L_{a_{p} a_{c}} & L_{a_{p} b_{c}} & L_{a_{p} c_{c}} \\
L_{b_{p} a_{c}} & L_{b_{p} b_{c}} & L_{b_{p} c_{c}} \\
L_{c_{p} a_{c}} & L_{c_{p} b_{c}} & L_{c_{p} c_{c}}
\end{array}\right) \\
& L_{a_{p} a_{c}}=L_{b_{p} c_{c}}=L_{c_{p} b_{c}}=L_{p c_{\max }} \cos \left(P_{p}+P_{c}\right) \theta_{r m} \\
& L_{a_{p} b_{c}}=L_{b_{p} a_{c}}=L_{c_{p} c_{c}}=L_{p c_{\max }} \cos \left(\left(P_{p}+P_{c}\right) \theta_{r m}-\frac{2 \pi}{3}\right) \\
& L_{a_{p} c_{c}}=L_{b_{p} b_{c}}=L_{c_{p} a_{c}}=L_{p c_{\max }} \cos \left(\left(P_{p}+P_{c}\right) \theta_{r m}+\frac{2 \pi}{3}\right) \\
& \left(L_{a b c_{c}-a b c_{p}}\right)=\left(L_{a b c_{p}-a b c_{c}}\right)^{T}
\end{aligned}
$$

The electromagnetic torque of the power and control winding are expressed as:

$$
T_{p}=\left(i_{a b c_{p}} T\right) \frac{d}{d \theta_{r m}}\left(L_{a b c_{p}-a b c_{c}}\right)\left(i_{a b c_{c}}\right)
$$




$$
T_{c}=\left(i_{a b c_{c}}{ }^{T}\right) \frac{d}{d \theta_{r m}}\left(L_{a b c_{c}-a b c_{p}}\right)\left(i_{a b c_{p}}\right)
$$

where the superscript " $T$ " denotes the matrix transpose.

From which, the overall electromagnetic torque of the BDFRG can be obtained as the summation of the electromagnetic torque of the two-stator windings as follows:

$$
T_{e}=T_{p}+T_{c}
$$

It is well known that, the presented abc-axis dynamic model of the BDFRG is non-linear model because of the time-varying mutual inductances as illustrated in (16). When the all variables associated with the abc-axis dynamic model are transformed to a fictitious dq-axis reference frame, all the time-varying inductances can be eliminated. Therefore, the proposed analysis is based on the dq- axis dynamic model.

Fig. 4 shows the phase axis relationship of the power and control windings with an opposite sequence of control winding with respect to that of power winding. The transformation matrices of the abc-axis variables of the power and the control windings to dqo-axis arbitrary reference frame can be written as follows:

$$
\begin{aligned}
& K_{p}=\frac{2}{3}\left(\begin{array}{ccc}
\cos \theta_{r p} & \cos \left(\theta_{r p}-\frac{2 \pi}{3}\right) & \cos \left(\theta_{r p}+\frac{2 \pi}{3}\right) \\
-\sin \theta_{r p} & -\sin \left(\theta_{r p}-\frac{2 \pi}{3}\right) & -\sin \left(\theta_{r p}+\frac{2 \pi}{3}\right) \\
\frac{1}{2} & \frac{1}{2} & \frac{1}{2}
\end{array}\right) \\
& K_{c}=\frac{2}{3}\left(\begin{array}{ccc}
\cos \theta_{r c} & \cos \left(\theta_{r c}+\frac{2 \pi}{3}\right) & \cos \left(\theta_{r c}-\frac{2 \pi}{3}\right) \\
-\sin \theta_{r c} & -\sin \left(\theta_{r c}+\frac{2 \pi}{3}\right) & -\sin \left(\theta_{r c}-\frac{2 \pi}{3}\right) \\
\frac{1}{2} & \frac{1}{2} & \frac{1}{2}
\end{array}\right)
\end{aligned}
$$

where

$$
\begin{gathered}
\theta_{r p}=\theta=P_{p} * \theta_{f} \\
\theta_{r c}=\left(\theta_{r}-\theta\right) \\
\theta_{r}=\left(P_{p}+P_{c}\right) * \theta_{r m}
\end{gathered}
$$




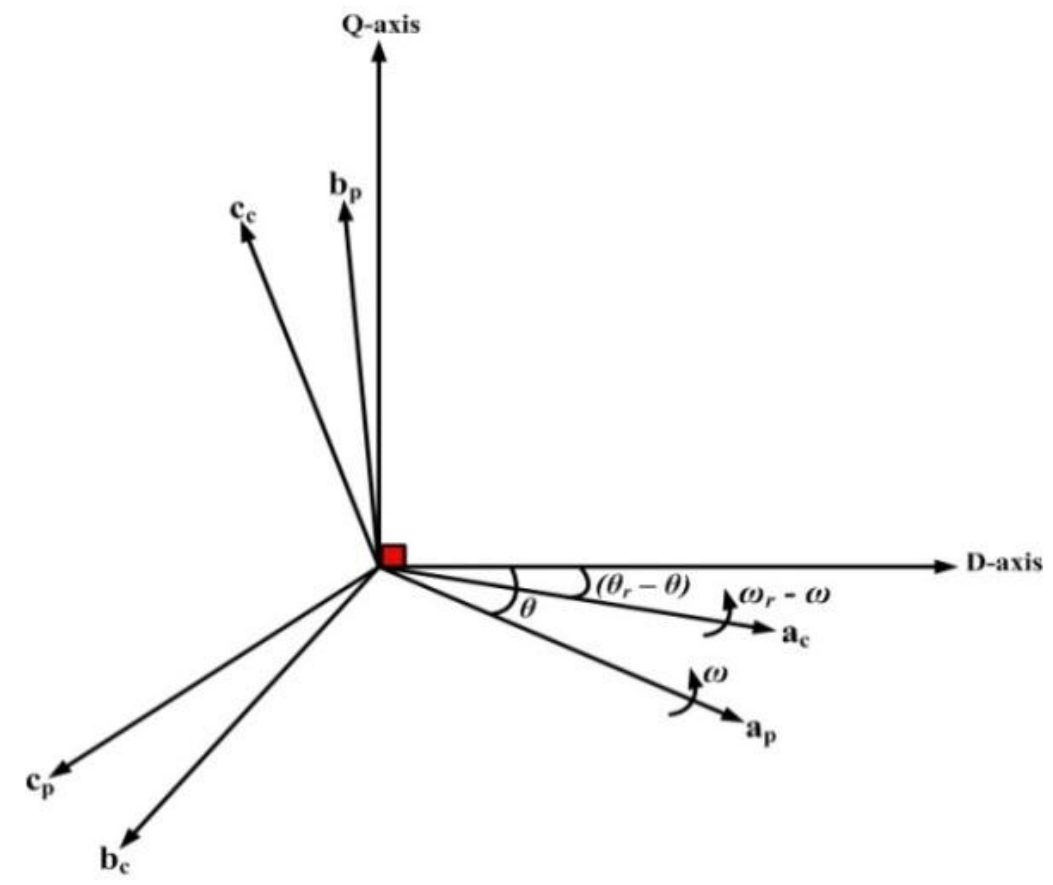

Fig.4.abc-axis and dq-axis relationship

The final dq-axis model of the wind-driven BDFRG system can be summarized as follows: The dq-axis voltage equations of the power and control windings can be written as:

$$
\begin{aligned}
& V_{d_{p}}=r_{p} i_{d_{p}}+\frac{d}{d t} \lambda_{d_{p}}-\omega \lambda_{q_{p}} \\
& V_{q_{p}}=r_{p} i_{q_{p}}+\frac{d}{d t} \lambda_{q_{p}}+\omega \lambda_{d_{p}} \\
& V_{d_{c}}=r_{c} i_{d_{c}}+\frac{d}{d t} \lambda_{d_{c}}-\left(\omega_{r}-\omega\right) \lambda_{q_{c}} \\
& V_{q_{c}}=r_{c} i_{q_{c}}+\frac{d}{d t} \lambda_{q_{c}}+\left(\omega_{r}-\omega\right) \lambda_{d_{c}}
\end{aligned}
$$

where

$$
\begin{aligned}
& \omega=P_{p} * \omega_{f} \\
& \omega_{r}=\left(P_{p}+P_{c}\right) * \omega_{r m}
\end{aligned}
$$

In addition, the corresponding flux linkage relations are given by:

$$
\begin{aligned}
& \lambda_{d_{p}}=L_{p} i_{d_{p}}+L_{p c} i_{d_{c}} \\
& \lambda_{q_{p}}=L_{p} i_{q_{p}}-L_{p c} i_{q_{e}} \\
& \lambda_{d_{c}}=L_{c} i_{d_{c}}+L_{p c} i_{d_{p}}
\end{aligned}
$$




$$
\lambda_{q_{c}}=L_{c} i_{q_{c}}-L_{p c} i_{q_{p}}
$$

where

$$
\begin{aligned}
& L_{p}=L_{l p}+\frac{3}{2} L_{m p} \\
& L_{c}=L_{l c}+\frac{3}{2} L_{m c} \\
& L_{p c}=\frac{3}{2} \mathrm{~L}_{p_{\max }}
\end{aligned}
$$

The electromagnetic torque expression can be written as:

$$
T_{e}=\left(\frac{3}{2}\right) * L_{p c} *\left(P_{p}+P_{c}\right) *\left(i_{d_{p}} i_{q_{c}}+i_{q_{p}} i_{d_{c}}\right)
$$

The electromechanical equation of the overall wind-driven BDFRG system referred to generator side can be expressed as:

$$
\left(J_{r}+n_{g}{ }^{2} J_{g}\right) \frac{d \omega_{r m}}{d t}=n_{g} T_{t}+n_{g}{ }^{2} T_{g}-\left(B_{r}+n_{g}{ }^{2} B_{g}\right) \omega_{r m}
$$

On the other hand, the active-power expressions of the power and control windings are given by:

$$
\begin{aligned}
& P_{\text {power }}=\left(\frac{3}{2}\right)\left(V_{d_{p}} i_{d_{p}}+V_{q_{p}} i_{q_{p}}\right) \\
& P_{\text {control }}=\left(\frac{3}{2}\right)\left(V_{d_{c}} i_{d_{c}}+V_{q_{c}} i_{q_{c}}\right)
\end{aligned}
$$

\section{Scalar V/f Control for Maximum Power Tracking}

It is well known that, in order to extract the maximum power from the wind turbine, the tip-speed ratio must equal its optimal value. Therefore, the generator speed should vary with wind-speed variations to maintain the tip-speed ratio at that proper value according to (3). Moreover, it is obvious from (1) that for a constant power winding frequency (grid connected), the control winding frequency should be varied to vary the rotor speed of BDFRG. In this paper a proposed scalar V/f control is used to achieve this strategy. Fig. 5 shows the main structure of proposed scalar V/f control method for maximum wind-power extraction.

In addition to extract the maximum power from the wind turbine, the proposed control system aims at limiting the starting current of the control winding below the rated value of the used converter. This is due to a reduced power rating of the control winding converter.

In order to achieve a good soft starting, the BDFRG is started as an induction machine by shorting the control winding terminals using the auxiliary switches $S_{1}$ and $S_{2}$ as shown in Fig. 5. In other words, $S_{1}$ is closed and $S_{2}$ is opened during this period up to reaching a speed approximately equals the rated value. Then, the bi-directional converter is switched into the control windings with a command frequency evaluated directly from the command generator speed by closing the switches $S_{2}$ and $S_{3}$ and opening the switches $S_{1}$ and $S_{4}$. 
The command control winding frequency can be expressed as:

$$
f_{c}^{*}=f_{p}-\left(\frac{\omega_{\text {sync }} *\left(P_{p}+P_{c}\right)}{2 \pi}\right)
$$

where $\omega_{\text {syne }}$ denotes the command generator speed.

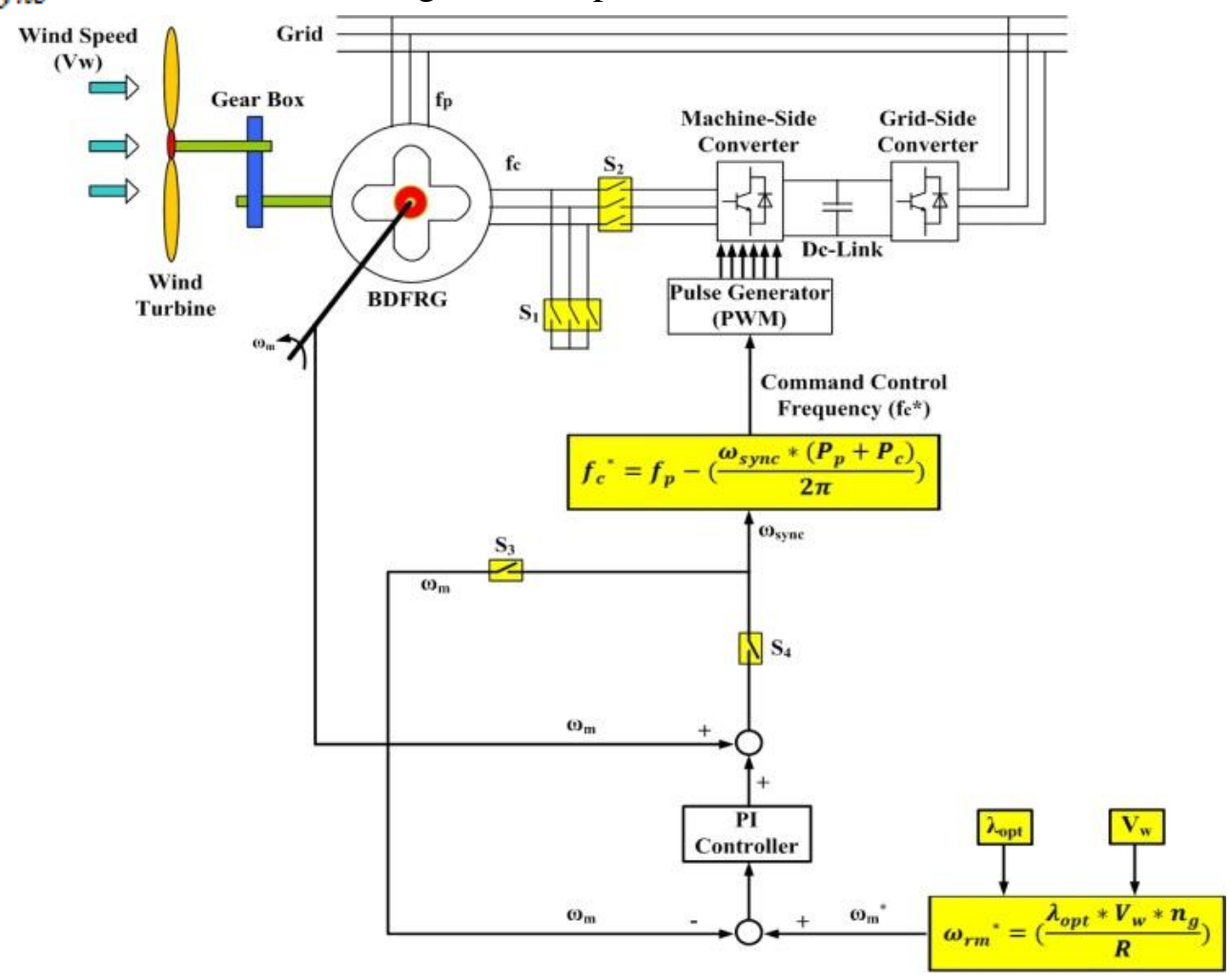

Fig. 5.Main structure of scalar V/f control for maximum power tracking

After these two steps for soft starting, the proposed scalar V/f closed loop control system will be activated by closing the switches $S_{2}$ and $S_{4}$ and opening the switches $S_{1}$ and $S_{3}$. The reference generator speed, $\omega_{r m}{ }^{*}$ can be evaluated directly by setting the optimal tip-speed ratio and measuring the wind speed. The evaluated reference speed is then compared to the actual generator speed and the error is controlled using a simple PI-controller for getting the command generator speed as shown in Fig. 5. Aiding with (35) the command control frequency can be easily determined, from which the required gating signals of the control-winding converter can be obtained using sinusoidal PWM technique.

\section{Simulation Results}

In order to confirm the validity of the proposed control technique, a sample of simulation results is introduced. The presented simulation results are obtained based on a six/two-pole, $4.5 \mathrm{~kW}$ BDFRG driven by an appropriate wind turbine. All data related to the overall system parameters are listed in the appendix section [10]-[11].

It can be observed from Fig. 3 that the optimal tip-speed ratio of the employed wind turbine $\lambda_{\text {opt }}$ equals 8.1 and the corresponding maximum power coefficient, $c_{p_{\max }}$ equals 0.48 at zero value of blade pitch-angle. The torque-speed profile of the wind-driven BDFRG is presented in Fig. 6 
indicating the optimal values of BDFRG input-torque and the corresponding rotor speed according to the optimal tip-speed ratio.

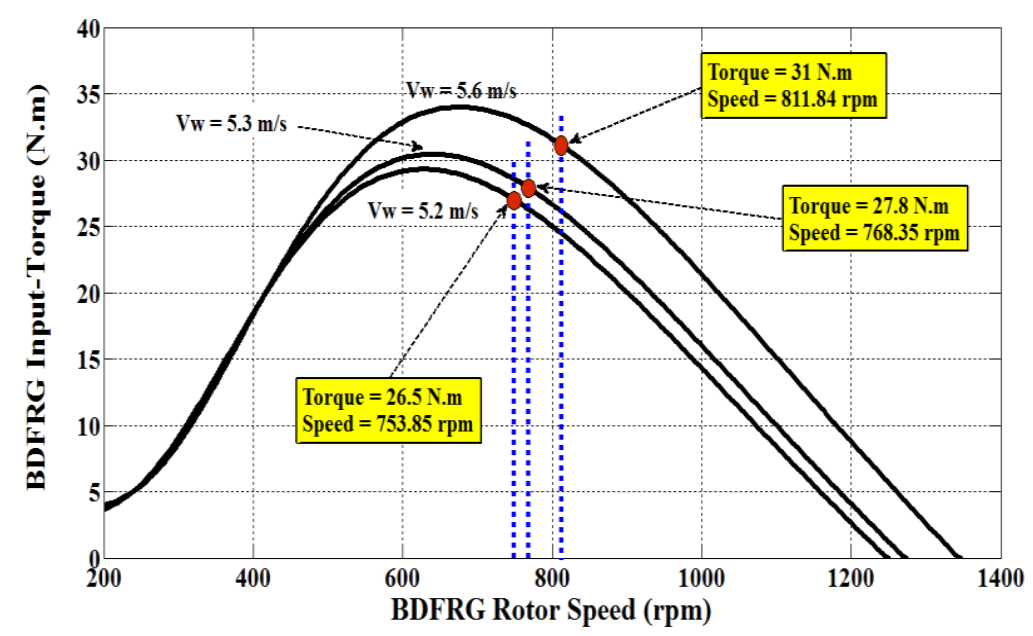

Fig. 6.Torque-speed profile of the simulated wind-driven BDFRG

In the simulation process, the capability of maximum power tracking using a scalar V/f control has been studied for wind-speed variations shown in Fig. 7.

Firstly, the BDFRG is freely accelerated with a short circuited control winding terminals for soft starting purpose [10] up to 2.5 seconds. Then, the partially power rating converter is switched into the control windings of the generator with a command control frequency evaluated directly aiding with (35), using the actual generator speed during the short circuit period. During this period, a simple PWM technique is used to control the voltage and frequency of the control winding up to 5.5 seconds. Hence, a complete scalar V/f closed loop control system is activated for maximum wind-power extraction.The response of the control winding phase current during different periods is shown in Fig. 8.

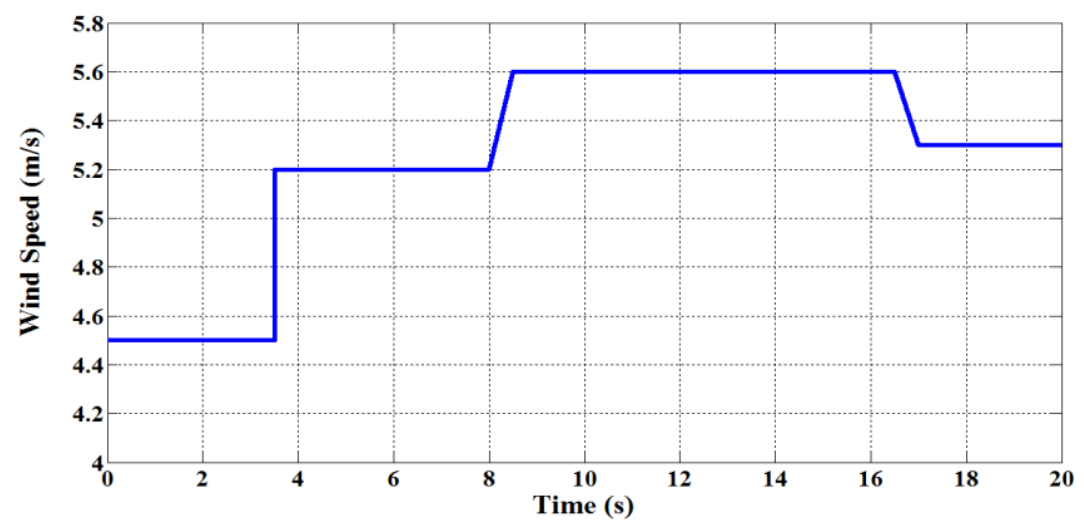

Fig. 7.Wind-speed variations 


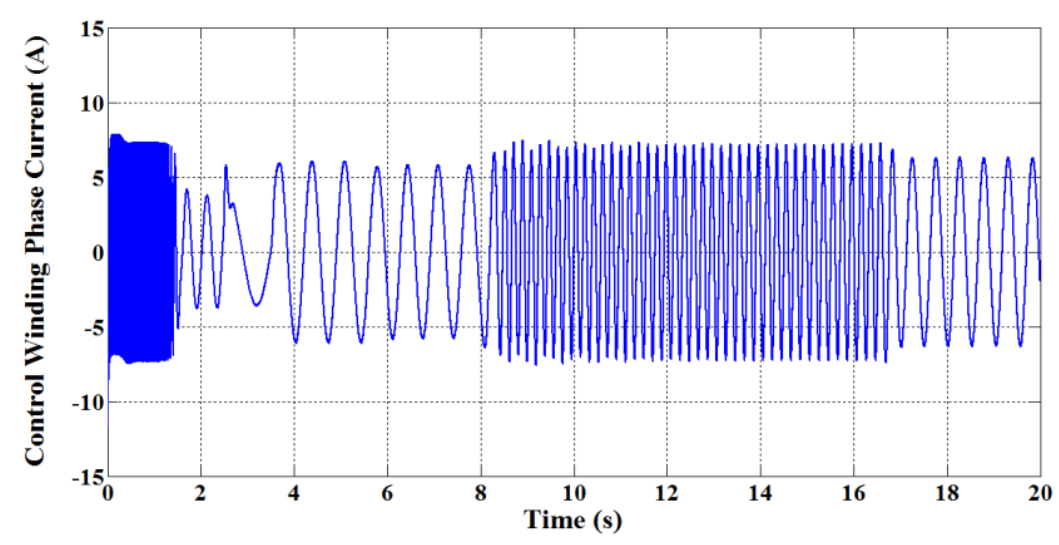

Fig. 8.Control winding phase current

It can be observed that the converter over-current is completely avoided when the converter is switched into the control windings after a small short circuit period of 2.5 seconds.

Under the same previously stated conditions, the actual generator rotor-speed response is shown in Fig. 9. Moreover, the response of wind turbine power coefficient and the corresponding electromagnetic torque are shown in Fig. 10 and Fig. 11 respectively.

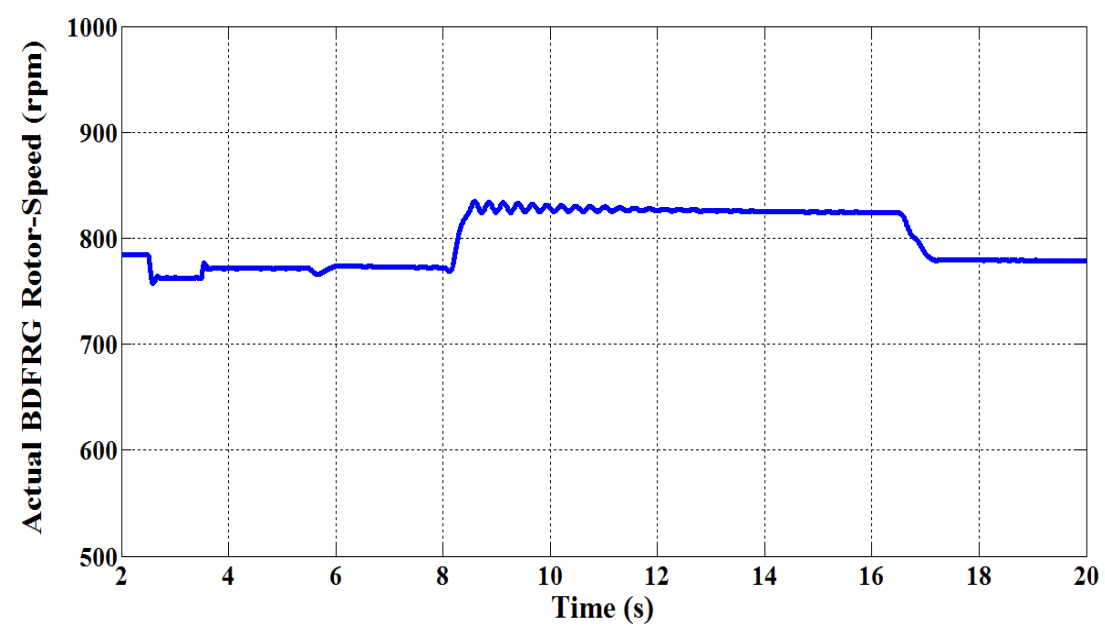

Fig. 9.Actual generator speed response

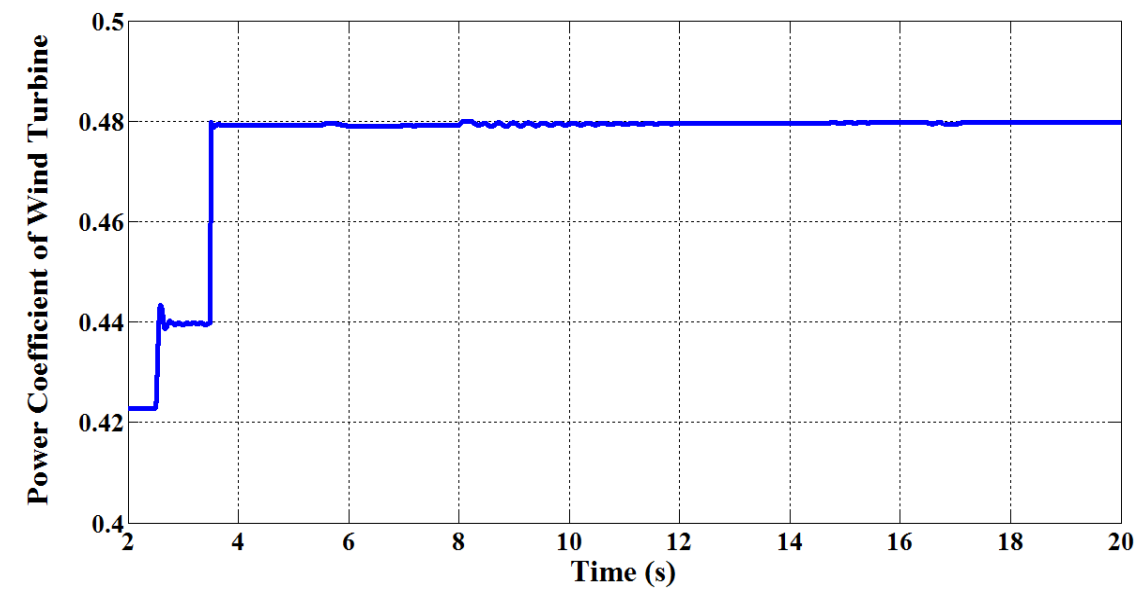

Fig. 10.Wind turbine power coefficient 


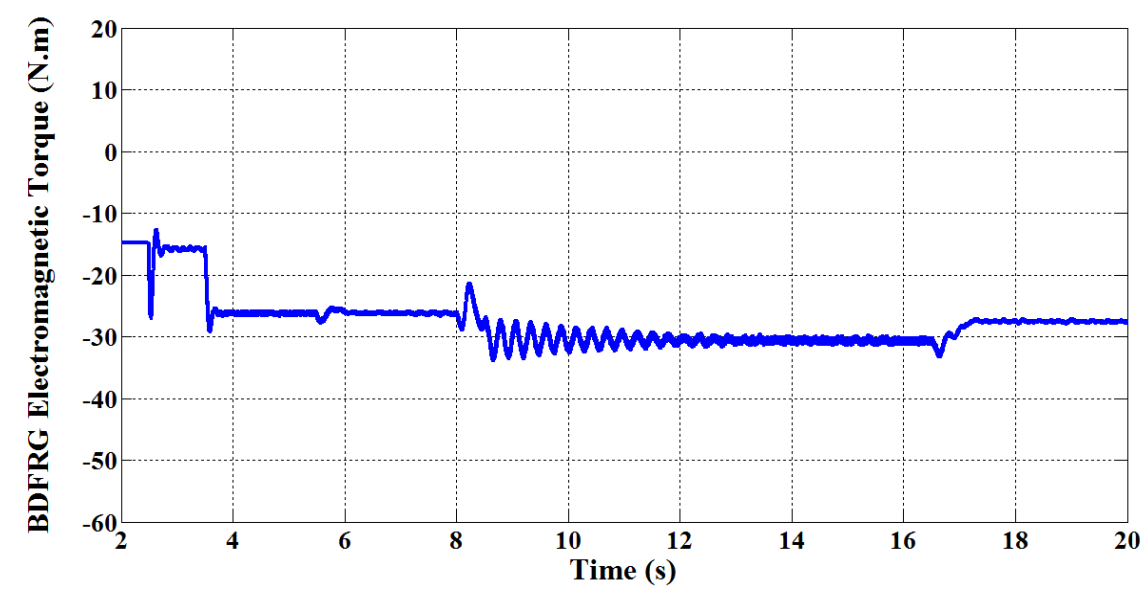

Fig. 11.Generator electromagnetic torque

Table I summarizes the system behaviour under different operating conditions using the proposed control strategy.

Table I Simulation results of the proposed control method

\begin{tabular}{|c|c|c|c|c|c|c|}
\hline \multirow{3}{*}{$\begin{array}{l}\text { Operating } \\
\text { Region }\end{array}$} & \multicolumn{3}{|c|}{ Soft Starting Steps } & \multirow{2}{*}{\multicolumn{3}{|c|}{$\begin{array}{l}\text { Closed Loop Control System for } \\
\text { Maximum Wind-Power Extraction }\end{array}$}} \\
\hline & $\begin{array}{l}\text { Short } \\
\text { circuited } \\
\text { control } \\
\text { winding }\end{array}$ & \multicolumn{2}{|c|}{$\begin{array}{l}\text { Switching the } \\
\text { converter into the } \\
\text { control winding }\end{array}$} & & & \\
\hline & $\begin{array}{c}0 \\
\text { to } \\
2.5\end{array}$ & $\begin{array}{l}2.5 \\
\text { to } \\
3.5\end{array}$ & $\begin{array}{l}3.5 \\
\text { to } \\
5.5\end{array}$ & $\begin{array}{c}5.5 \\
\text { to } \\
8\end{array}$ & $\begin{array}{c}8.5 \\
\text { to } \\
16.5\end{array}$ & $\begin{array}{l}17 \\
\text { to } \\
20\end{array}$ \\
\hline $\begin{array}{l}\text { Wind speed } \\
\qquad(\mathrm{m} / \mathrm{s})\end{array}$ & 4.5 & 4.5 & 5.2 & 5.2 & 5.6 & 5.3 \\
\hline $\begin{array}{l}\text { Control winding } \\
\text { frequency }(\mathrm{Hz})\end{array}$ & -2.283 & -0.83 & $1.47^{-}$ & -1.33 & -4.4 & $1.6^{-}$ \\
\hline $\begin{array}{c}\text { BDFRG } \\
\text { speed (rpm) }\end{array}$ & $\begin{array}{l}784.2 \\
5\end{array}$ & 762.5 & 772 & 770 & 816 & 774 \\
\hline $\begin{array}{c}\text { Power } \\
\text { coefficient }\end{array}$ & 0.423 & 0.44 & $\begin{array}{l}0.47 \\
8\end{array}$ & 0.48 & 0.48 & $8^{0.4}$ \\
\hline $\begin{array}{c}\text { BDFRG } \\
\text { electromagnetic } \\
\text { torque (N.m) }\end{array}$ & -14.7 & -15.5 & $26.8^{-}$ & -26.5 & -31 & $27.5^{-}$ \\
\hline
\end{tabular}


The simulation results shown in Table I describe the system behaviour in both soft starting steps and closed loop control system for maximum wind-power extraction.

The obtained results ensure the effectiveness of the proposed control strategy to maintain the tip-speed ratio at its optimal value under wind-speed variations.

The negative sign associated with the electromagnetic torque, shown in Fig. 11, proves that the machine is effectively in generating mode.

It can be observed from Fig. 11 that the response of the generator electromagnetic torque has been changed for wind-speed variations to track the optimal values, shown in Fig. 6, for maximum wind-power extraction.

\section{Conclusions}

This paper has proposed a scalar V/f control strategy of a grid-connected wind-driven BDFRG for maximum wind-power extraction under wind-speed variations. A detailed abc-axis and dq-axis dynamic model of the BDFRG has been presented. In addition, the over-current of the employed converter has been avoided using a suggested soft starting method. The presented simulation results show a good transient response using the proposed control technique along with wind-speed variations. In addition, the results ensure the capability of the presented control system for maximum wind-power extraction of the proposed wind-generating system.

\section{References}

[1] J. Douglas, "Renewables on the rise," Electric Power Research Institute (EPRI) Journal, June 1991.

[2] B. Wu, Y. Lang, N. Zargari, and S. Kouro, "Power Conversion and Control of Wind Energy Systems," Wiley-IEEE Press, 2011.

[3] S. M. Allam, A. M. Azmy, M. A. El-Khazendar, and A. L. Mohamadein, "Dynamic analysis of a BDFIM with a simple-proposed modification in the cage-rotor," The 13th International Middle-East Power Systems Conference (MEPCON'2009), Egypt, Vol. 1, Dec. 2009, pp. 356-360.

[4] B. Hopfensperger, and D. J. Atkinson, "Doubly-fed a.c. machines: classification and comparison," European Power Electronics Conference, EPE 2001, PP. P1-P17.

[5] F. Liang, L. Xu, and T. A. Lipo, "d-q analysis of a variable speed doubly ac excited reluctance motor," Electrical Machines and Power Systems, Vol. 19, No. 2, Mar. 1991, pp. 125138.

[6] R. E. Betz and M. G. Jovanovic, "Introduction to the space vector modelling of the brushless doubly-fed reluctance machine," Electric Power Components and Systems, Vol. 31, No. 8, 2003, pp. 729-755.

[7] F. Valenciaga and P. F. Puleston, "Variable structure control of a wind energy conversion system based on a brushless doubly fed reluctance generator," IEEE Transactions on Energy Conversion, Vol. 22, No. 2, June 2007, pp. 499-506.

[8] L. Xu and Y. Tang, "A novel wind-power generating system using field orientation controlled doubly-excited brushless reluctance machine," Proceeding of the IEEE IAS Annual Meeting, 1992, pp. 408-413.

[9] Yong Liu, Lingzhi Yi, Hongbin Pan, and ZhiyongLan, "The simulation study for Brushless doubly-fed generator wind power system based on fuzzy control," Power and Energy Engineering Conference (APPEEC), 2010 Asia-Pacific , March 2010, pp. 1-4. 
[10] S. Ademi and M. Jovanovic, "Vector control strategies for brushless doubly-fed reluctance wind generators," Environment-Friendly Energies and Applications (EFEA), 2012 2nd International Symposium on, 25-27 June 2012, pp. 44-49.

[11] J. Sandoval-Moreno, G. Besancon, and J. J. Martinez, "Observer-based maximum power tracking in wind turbines with only generator speed measurement," 2013 European Control Conference (ECC), 17-19 July 2013, pp. 478-483.

\section{Appendix}

BDFRG Parameters [10]:

\begin{tabular}{|c|c|}
\hline $\begin{array}{c}\text { Rated Line } \\
\text { Voltage } \\
\text { Rated } \\
\text { Frequency }\end{array}$ & $380 \mathrm{~V}$ \\
\hline Rated Current & $70 \mathrm{~Hz}$ \\
\hline$r_{p}$ & $3.781 \Omega$ \\
\hline$r_{c}$ & $2.441 \Omega$ \\
\hline$L_{p}$ & $0.41 \mathrm{H}$ \\
\hline$L_{c}$ & $0.316 \mathrm{H}$ \\
\hline$L_{p c}$ & $0.3 \mathrm{H}$ \\
\hline $\begin{array}{c}\text { Rotor Inertia, } \\
J_{g}\end{array}$ & $0.2 \mathrm{~kg} \cdot \mathrm{m}^{2}$ \\
\hline
\end{tabular}

Wind Turbine Parameters [11]:

\begin{tabular}{|c|c|}
\hline Rated Power & $6.0 \mathrm{~kW}$ \\
\hline $\begin{array}{c}\text { Turbine } \\
\text { Radius, R }\end{array}$ & $4.0 \mathrm{~m}$ \\
\hline $\begin{array}{c}\text { Wind Speed } \\
\text { Range }\end{array}$ & $\begin{array}{c}2-12 \\
\mathrm{~m} / \mathrm{s}\end{array}$ \\
\hline $\begin{array}{c}\text { Turbine } \\
\text { Inertia, } J_{r}\end{array}$ & $1.5 \mathrm{~kg} \cdot \mathrm{m}^{2}$ \\
\hline $\begin{array}{c}\text { Gearbox Ratio, } \\
n_{g}\end{array}$ & 7.5 \\
\hline
\end{tabular}

